\title{
Diffuse Pulmonary Cysts in Metastatic Angiosarcoma
}

\author{
Takayuki Takimoto $^{1,2}$, Akio Osa ${ }^{1}$, Satomu Morita ${ }^{1}$ and Kinya Abe ${ }^{1}$
}

Key words: diffuse cystic lung disease, diffuse pulmonary cyst, metastatic angiosarcoma

(Intern Med 59: 457-458, 2020)

(DOI: 10.2169/internalmedicine.3644-19)

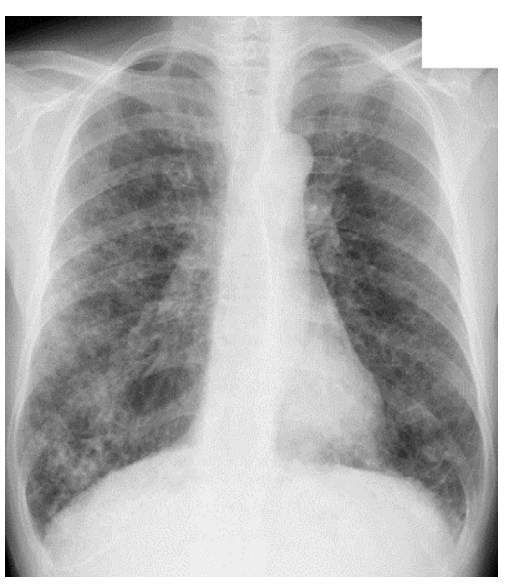

Picture 1.

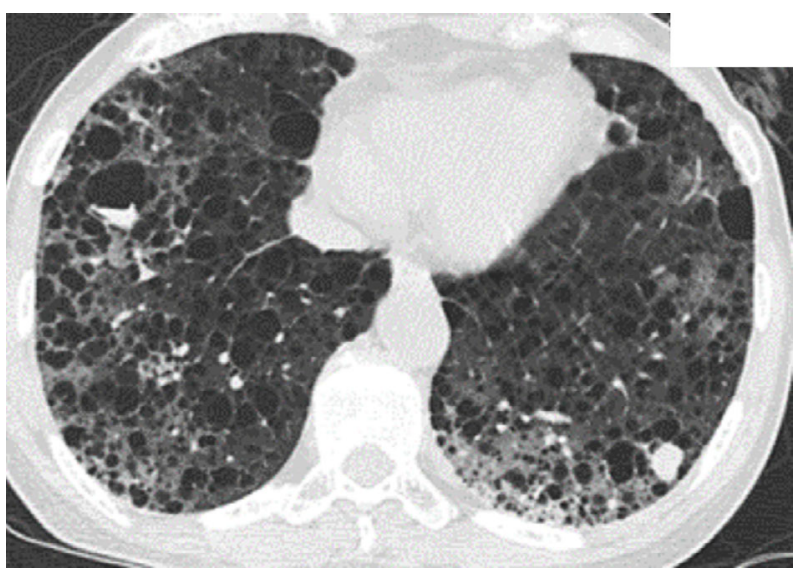

Picture 2.

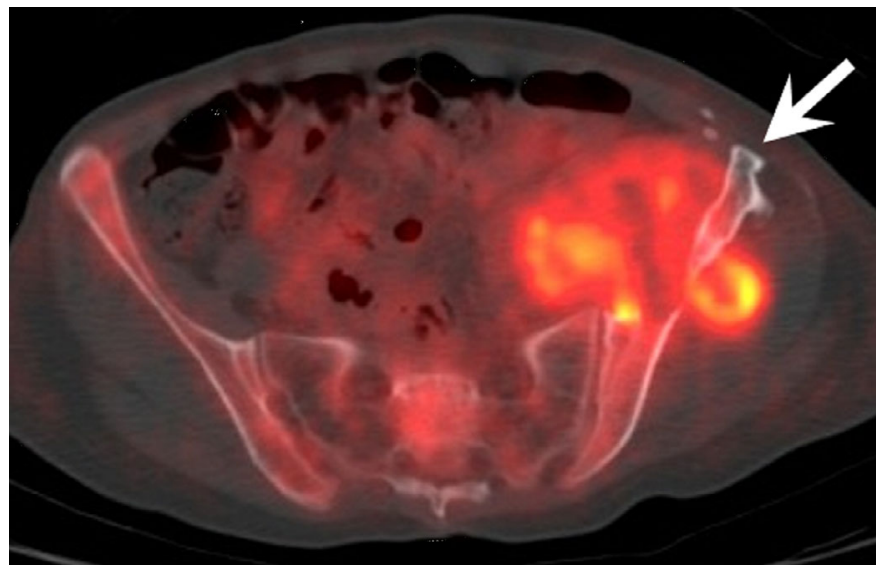

Picture 3.

A 60-year-old nonsmoking woman presented with hemoptysis. Chest radiograph showed a diffuse reticulonodular shadow (Picture 1), and thoracic computed tomography demonstrated diffuse thin-walled cysts, with multiple nodular shadows and ground glass opacities, in both lung fields
(Picture 2). Fluorodeoxyglucose (FDG)-positron emission tomography revealed an $8-\mathrm{cm}$ tumor in the left iliac bone (Picture 3), which was histologically diagnosed as angiosarcoma. The uptake of FDG was also observed in multiple lung nodules (Picture 4). Diffuse cystic lung diseases can be

${ }^{1}$ Department of Internal Medicine, Toyonaka Municipal Hospital, Japan and ${ }^{2}$ Department of Internal Medicine, National Hospital Organization Kinki-Chuo Chest Medical Center, Japan

Received: July 10, 2019; Accepted: August 8, 2019; Advance Publication by J-STAGE: September 18, 2019

Correspondence to Dr. Takayuki Takimoto, takimoto.takayuki.ra@mail.hosp.go.jp 


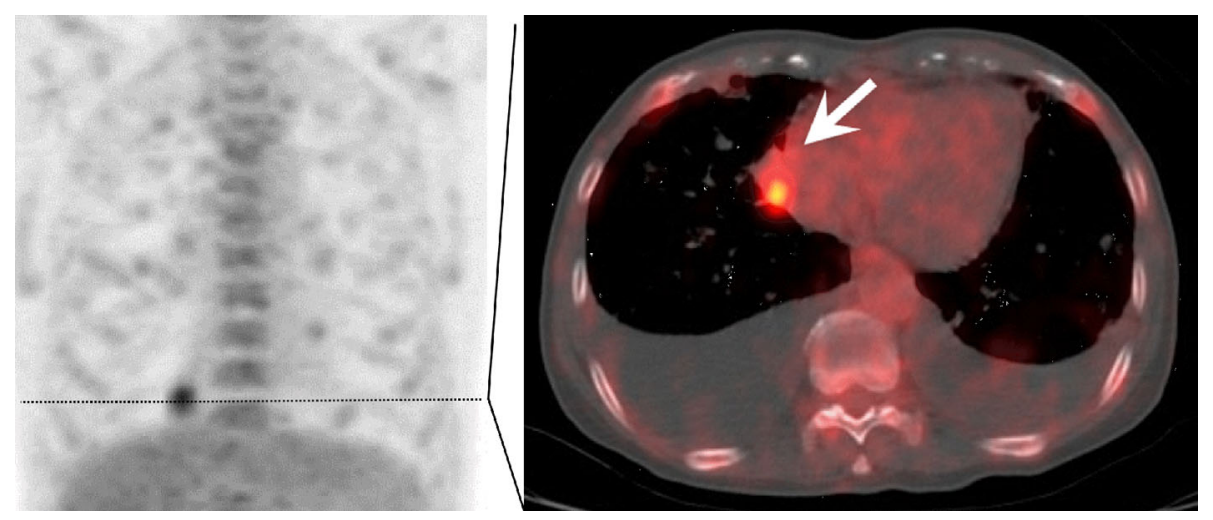

Picture 4.

broadly classified according to the underlying etiology as those caused by metastasizing neoplasms, lymphoproliferative disorders, infections, interstitial lung diseases, smoking, and congenital or developmental defects (1). A cystic pulmonary metastasis, as was seen in this case, is a thin-walled, bulla-like lesion with or without nodular lesions $(1,2)$. Three possible mechanisms underlying cyst formation have been proposed: central necrosis, infiltration by malignant cells of preexisting bullae, and small airway distension through a valve effect caused by malignant cell infiltration.

The authors state that they have no Conflict of Interest (COI).

\section{References}

1. Gupta N, Vassallo R, Wikenheiser-Brokamp KA, McCormack FX. Diffuse cystic lung disease. Part I. Am J Respir Crit Care Med 191: 1354-1366, 2015.

2. Tateishi U, Hasegawa T, Kusumoto M, et al. Metastatic angiosarcoma of the lung: spectrum of CT findings. Am J Roentgenol 180: 1671-1674, 2003.

The Internal Medicine is an Open Access journal distributed under the Creative Commons Attribution-NonCommercial-NoDerivatives 4.0 International License. To view the details of this license, please visit (https://creativecommons.org/licenses/ by-nc-nd/4.0/).

(C) 2020 The Japanese Society of Internal Medicine Intern Med 59: 457-458, 2020 